\title{
Plasma Membrane Calcium-Transporting ATPase 3
}

National Cancer Institute

\section{Source}

National Cancer Institute. Plasma Membrane Calcium-Transporting ATPase 3. NCI

Thesaurus. Code C113767.

Plasma membrane calcium-transporting ATPase 3 (1220 aa, $134 \mathrm{kDa}$ ) is encoded by the human ATP2B3 gene. This protein plays a role in both ATP hydrolysis and calcium transport. 